\title{
RESEARCH
}

\section{Comparison of Growth Pattern in Neonates on Breast Feed Versus \\ Formula Feed}

\author{
Singh Arun Kumar ${ }^{* 1}$, Singh Raj Kumar ${ }^{2}$, Shah Rajesh Prasad ${ }^{1}$, Ahmad Equbal ${ }^{3}$, Ansari Akhtar \\ Alam $^{4}$, Mansuri Mohammed Islam ${ }^{5}$ \\ ${ }^{1}$ Department of Paediatrics, BPKIHS, Dharan, Nepal \\ ${ }^{2}$ Department of Paediatrics, Kanti Bal Hospital, Kathmandu \\ ${ }^{3}$ Department of Paediatrics, Novel Medical College, Biratnagar, Nepal \\ ${ }^{4}$ Department of Pharmacology, National Medical College, Birgunj, Nepal \\ ${ }^{5}$ Department of Emergency, National Medical College, Birgunj, Nepal
}

\section{ABSTRACT}

Background: Breast milk and colostrums are the first feeding sources for infant, providing nutrients, growth factors and immunological components. So we conducted this study to compare the growth pattern of neonates on breast feed versus formula feed.

Methods: This study was done in the Department of Pediatrics, King Edward Medical University, Mayo Hospital, Lahore from 2015 July to 2016 July as cross sectional study. The Non Probability purposive sampling technique was used. Information on type of feeding was obtained from mothers. Subsequently neonates were divided in two groups on the basis of type of feeding (i.e. breast feeding or formula feeding).

Results: In this study the mean age of the patients was $16.56 \pm 6.26$ days and the mean gestational age of the patients was $8.52 \pm 0.97$ months. The male to female ratio of the patients was $1.3: 1$. Statistically there was significant difference found between the weight gain in study groups at $10^{\text {th }}, 14^{\text {th }}$ week and $4^{\text {th }}$ month follow up i.e. p-value $<0.05$.
Conclusion: The prevalence of breastfeeding in infants in our study was $52.3 \%$. Our results showed that the breast fed infants had better weight gain compared to formula fed infants; however there was no statistically significant difference in gain in length between breast fed and formula fed infants.

Keywords: Exclusive Breast feeding, Formula feeding, Length, Infants, Weight

*Corresponding Author: Dr. Arun Kumar Singh, BPKIHS, Dharan, Nepal, Email: arunsinghnepal@ gmail.com

\section{INTRODUCTION}

Breast milk and colostrums are the first feeding sources of infant, providing nutrients, growth factors and immunological components, which are crucial for the newborn's optimum development and health. Duration of exclusive breast feeding \& time of introduction of solid foods is a key factor that may influence allergy development. ${ }^{1}$

Breast feeding is one of most effective ways to ensure child health \& survival. Failure to breast feed during the 1st 6-months of life contributes to 
over a million preventable child death each year. There are well established benefits to the mother and to the child's growth, mental development and immunological system. ${ }^{2}$

The WHO recommends that an infant should be exclusively breast fed for the six months and then continued breast feeding for two years with supplemental foods. Globally less than $40 \%$ of infants less than six months of age are exclusively breast fed. Increasing this rate can be achieved by improving breast feeding support for mothers and families. ${ }^{2}$

The incidence of breast feeding has recently been found to be $81 \%$ in the London UK (an increase from $76 \%$ in 2005). The incidence of breast feeding was only $62 \%$ in $1990 .^{3}$ The incidence of Exclusive breast feeding in Pakistan was reported by about $54 \%$ of the mothers. ${ }^{4}$

Breastfeeding, also known as nursing, is the feeding of babies or young children with milk from the female breast. ${ }^{7}$ Breastfeeding should be started during the hour after birth and allowed as the baby wishes. ${ }^{8}$ During the first few weeks of life babies may nurse eight to twelve times a day. The duration of a feeding is usually ten to fifteen minutes on each breast. The frequency of feeding decreases as the child gets older. ${ }^{9}$ Some mothers pump milk so that it can be used later when their child is being cared for by others. Breastfeeding benefits both mother and baby. Infant formula does not have many of the benefits. ${ }^{10}$

It is estimated that greater than a million babies could be saved globally per year through greater breastfeeding. Breastfeeding decreases the risk of respiratory tract infections and diarrhea. This is true both in developing and developed countries. Other benefits include a lower risk of asthma, food allergies, celiac disease, type-1 diabetes and leukemia. Breastfeeding may also decrease the risk of obesity in adulthood and improved cognitive development. ${ }^{7}$

Benefits of breastfeeding for the mother include less blood loss following delivery, better uterus shrinkage, weight loss and less postpartum depression. It also increases the time before menstruation and fertility returns, known as lactational amenorrhea. Long term benefits may include a decreased risk of breast cancer, cardiovascular disease and rheumatoid arthritis. Breastfeeding is less expensive for the family than infant formula. ${ }^{11}$

Health groups, such as World Health Organization (WHO), support six months of exclusive breastfeeding. ${ }^{12}$ This means that no other foods (other than vitamin) D are typically given. Continued partial breastfeeding until at least a year of age is recommended. Globally about $38 \%$ of infants are just breastfed during their first six months of life In the United States about $75 \%$ of women begin breastfeeding and about $43 \%$ breastfed until six months. Medical conditions that do not allow breastfeeding are uncommon. During breastfeeding drugs and certain medications are not recommended. ${ }^{12}$

But a study found that there is no significant difference $(p>0.05)$ between infants either on breast feed or formula feed in their length and weight (breast feed: Weight $=6835.5 \pm 782 \mathrm{grams}$ and Length $=63.85 \pm 2.35 \mathrm{cms}$ vs. formula feed: Weight $=6922 \pm 703$ grams and Length $=$ $63.9 \pm 1.6 \mathrm{cms})$. The growth was slightly better in formula feeding during first 6 months of life. ${ }^{5}$ But another study also found that there are infants on breast feed have better weight gain (6712 \pm 626.5 grams) as compared to infants on formula feeding (6356 \pm 667 grams), moreover, the length was also greater with breast feeding (i.e. $63.15 \pm 2.14 \mathrm{cms}$ of breast feed infants vs. $62.45 \pm 2.33 \mathrm{cms}$ of formula feed infants, $\mathrm{p}<0.05){ }^{6}$

The rationale of my study is to determine the frequency of exclusive breast feeding and growth pattern of neonates presenting in Department of Pediatrics, King Edward Medical University, Mayo Hospital, Lahore of a tertiary care hospital. Infant formula is the only alternative to breast milk. It is available in cartons or as powder to be made up as directed. But mother feed is better in all means. So we conducted this study to assess the growth pattern of infants in local population who are on either formula feed or breast feed. 


\section{MATERIAL AND METHODS}

\section{Operational Definition}

Breast Fed: It was defined as neonate on exclusively mother feed / breast feeding.

Formula Fed: It was defined as neonate on bottle feed or formula feed.

Measurement of Weight: It was measured as increase in weight of baby from baseline till 4 months of age in terms of grams measured by digital weighing scale.

Measurement of Length: It was measured as increase in length of baby from baseline till 4 months of age in terms of centimeters $(\mathrm{cms})$ measured by infantometer.

\section{Study Design}

Cross sectional study, Department of Pediatrics, King Edward Medical University, Mayo Hospital, Lahore. Sample size of 382 neonates was calculated with $95 \%$ confidence level, 5\% margin of error and taking expected percentage of exclusive breast feeding i.e. $54 \%$ in neonates presenting in Department of Pediatrics, King Edward Medical University, Mayo Hospital, Lahore. However 400 cases were enrolled. Non Probability, Purposive sampling technique.

\section{Inclusion Criteria}

Neonates with $<28$ days of age, Both genders and Neonates delivered at term (gestational age $>36$ weeks from maternal history)

\section{Exclusion Criteria}

Children having congenital heart diseases, tracheoesophageal fistula, cleft lip, cleft palate or with visible congenital deformity assessed through general physical examination, twin birth (on history),LBW (birth weight $<2500$ grams) on birth card, Sick babies (on clinical examination), Infants on exclusive breast feeding at start of study converted on bottle/formula feeding due to environmental circumstances like mother's health is not fit or she has conceived again and change in breast feeding practice (exclusive breast feeding/ formula feeding) during the follow-up period.

\section{DATA COLLECTION PROCEDURE}

400 neonates fulfilling inclusion criteria were enrolled from Department of Pediatrics, King Edward Medical University, Mayo Hospital, Lahore. A verbal consent was obtained from their parents \& ensuring confidentiality. Demographic variables (name, age, gestational age at birth, contact number) were also obtained. Feeding information was obtained from mothers. Then neonates were divided in two groups on the basis of type of feeding (i.e. breast feeding or formula feeding). Weight of neonate was measured by digital weighing scale. Neonate's length was measured $(\mathrm{cms})$ using an infantometer. The mothers were advised to visit Department of Pediatrics, King Edward Medical University, Mayo Hospital, Lahore, regularly till 4 months. Then again Weight and Length of infant was measured.

\section{DATA ANALYSIS PROCEDURE}

The data collected was analyzed by statistical program SPSS Version 18. Quantitative variables like age, gestational age, weight and length at time of first presentation and after 4 months was presented as mean and standard deviation. Qualitative variables like gender were presented as frequency and percentage. Both groups were compared by using t-test. $\mathrm{p} \leq 0.05$ was taken as significant. Chi-square test was applied. P-value $\leq 0.05$ was considered as significant.

\section{RESULTS}

In present study, total 400 cases were enrolled. The mean age of the cases was $16.56 \pm 6.26$ days with age range 7 to 27 days.

Table1 : Age Distribution of Study cases (days)

\begin{tabular}{|c|c|c|}
\hline \multirow{4}{*}{ Age (days) } & $\mathrm{n}$ & 400 \\
\cline { 2 - 3 } & Mean & 16.56 \\
\cline { 2 - 3 } & $\mathrm{SD}$ & 6.26 \\
\cline { 2 - 3 } & Minimum & 7 \\
\cline { 2 - 3 } & Maximum & 27 \\
\cline { 2 - 3 }
\end{tabular}


$57 \%$ patients were males and $43 \%$ patients were females (M:F ratio 1.3:1).

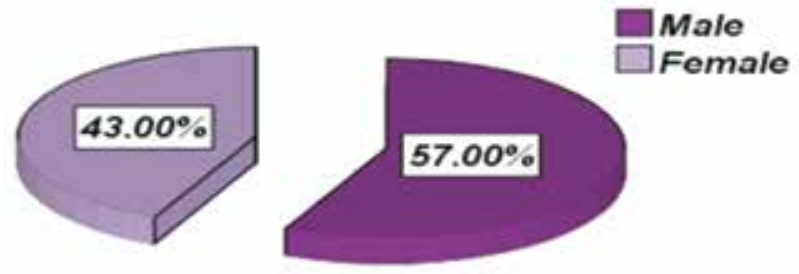

\section{Figure 1 : Sex distribution of Study cases}

The results showed that the mean weight of the study cases at $28^{\text {th }}$ day was $3244.75 \pm 445.75$ grams; at $6^{\text {th }}$ week the mean weight was $4745.00 \pm 853.99$ grams and at $10^{\text {th }}$ week the mean weight was $6428.75 \pm 1329.93$ grams, the mean weight at $14^{\text {th }}$ week was $6428.75 \pm 1329.93$ grams and at $4^{\text {th }}$ month the mean weight was $7372.50 \pm 1274.38$ grams.

Table 2 : Comparison of weight at different follow ups in both study groups

\begin{tabular}{|c|c|c|c|c|c|c|}
\hline \multirow{2}{*}{\multicolumn{2}{|c|}{ Mean }} & \multicolumn{2}{|c|}{ Group A } & \multicolumn{2}{|c|}{ Group B } & \multirow{2}{*}{ p-value } \\
\hline & & $\overline{\text { SD }}$ & Mean & SD & Mean & \\
\hline \multirow{5}{*}{ 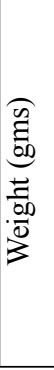 } & $\begin{array}{l}28^{\text {th }} \\
\text { day }\end{array}$ & 3225.36 & 448.07 & 3265.97 & 442.41 & 0.363 \\
\hline & $\begin{array}{l}6^{\text {th }} \\
\text { week }\end{array}$ & 4729.67 & 840.604 & 4761.78 & 870.302 & 0.708 \\
\hline & $\begin{array}{l}10^{\text {th }} \\
\text { week }\end{array}$ & 6830.14 & 1290.163 & 5989.53 & 1233.265 & 0.000 \\
\hline & \begin{tabular}{|l|}
$14^{\text {th }}$ \\
week
\end{tabular} & 6830.14 & 1290.163 & 5989.53 & 1233.265 & 0.000 \\
\hline & $\begin{array}{l}4^{\text {th }} \\
\text { month }\end{array}$ & 7825.36 & 1251.683 & 6876.96 & 1105.866 & 0.000 \\
\hline
\end{tabular}

\section{Group A= Breast feed Group $B=$ Formula feed}

In group $\mathrm{A}$, the mean length at $28^{\text {th }}$ day was $51.57 \pm 0.86 \mathrm{~cm}$ compared to group B $(51.55 \pm 0.86$ $\mathrm{cm})$. The mean length of study cases on $6^{\text {th }}$ week in group A was $55.88 \pm 1.73 \mathrm{~cm}$ and in group B $56.02 \pm 1.69 \mathrm{~cm}$. The mean length of study cases on $10^{\text {th }}$ week in group A was $59.88 \pm 1.73 \mathrm{~cm}$ and in group B $60.02 \pm 1.69 \mathrm{~cm}$. The mean length of study cases on $14^{\text {th }}$ week in group A was $62.46 \pm 0.85 \mathrm{cms}$ and in group B $62.59 \pm 0.89 \mathrm{~cm}$. Similarly at $4^{\text {th }}$ month in group A the mean length was $64.46 \pm 0.86 \mathrm{~cm}$ and in group B $64.59 \pm 0.88$ $\mathrm{cm}$. Statistically there was no significant difference between the mean lengths of study groups at follow up at $28^{\text {th }}$ day, $6^{\text {th }}, 10^{\text {th }}, 14^{\text {th }}$ week and $4^{\text {th }}$ months $(p$-value $=0.81,0.41,0.41,0.12$, 0.12 respectively).

Table 3 : Comparison of length at different follow ups in both study groups

\begin{tabular}{|c|c|c|c|c|c|c|}
\hline \multirow{2}{*}{\multicolumn{2}{|c|}{ Mean }} & \multicolumn{2}{|c|}{ Group A } & \multicolumn{2}{|c|}{ Group B } & \multirow{2}{*}{ p-value } \\
\hline & & SD & Mean & SD & Mean & \\
\hline \multirow{5}{*}{ 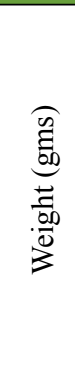 } & $\begin{array}{l}28^{\text {th }} \\
\text { day }\end{array}$ & 51.57 & 0.86 & 51.55 & 0.86 & 0.81 \\
\hline & $\begin{array}{l}6^{\text {th }} \\
\text { week }\end{array}$ & 55.88 & 1.73 & 56.02 & 1.69 & 0.41 \\
\hline & $\begin{array}{l}10^{\text {th }} \\
\text { week }\end{array}$ & 59.88 & 1.73 & 60.02 & 1.69 & 0.41 \\
\hline & $\begin{array}{l}14^{\text {th }} \\
\text { week }\end{array}$ & 62.46 & 0.85 & 62.59 & 0.89 & 0.12 \\
\hline & \begin{tabular}{|l|}
$4^{\text {th }}$ \\
month
\end{tabular} & 64.46 & 0.86 & 64.59 & 0.88 & 0.12 \\
\hline
\end{tabular}

\section{Group A= Breast feed}

Group B= Formula feed

\section{DISCUSSION}

This cross sectional survey was done determine the frequency of neonates on exclusively breast feeding and compare the growth in terms of length gain and weight gain between breast fed and formula fed infants.

According to our study results in their growth of weight at $10^{\text {th }}, 14^{\text {th }}$ week $\& 4^{\text {th }}$ month there is significant difference was found between the breast fed and formula fed baby. The greater weight was observed in breast fed infants than in formula fed infants. The mean weight in breast fed patients at 4 th month was $7825.36 \pm 1251.68 \mathrm{gms}$ and in formula fed infants it was $6876.96 \pm 1105.86$ gms i.e. $p$-value $=0.000$.

Our study results showed no difference among length of babies between the breast fed and formula fed infants. On $4^{\text {th }}$ month in breast fed infants the mean baby length of the patients was $64.46 \pm 0.86 \mathrm{cms}$ and in formula fed it was $64.59 \pm 0.88 \mathrm{cms}$ i.e. $\mathrm{p}$-value $=0.12$.

Agostoni, et al. concluded in their study that the growth pattern of breast fed and formula fed Italian infants differs in the first 12 months of life. Growth indices in breast fed groups was high at birth and closer than expected to the reference at 12 months, may reflect differences in genetic factors, intrauterine conditions, or both. ${ }^{6}$ 
On contrary a study by Ahmed, et al. showed that no statistical significant differences between the weight, length, head, and chest circumference to breast-fed and artificially fed infants during the second visit as regards to all anthropometric measurements. ${ }^{14}$

A study found that there is no significant difference $(p>0.05)$ between infants either on breast feed or formula feed in their length and weight (breast feed: Weight $=6835.5 \pm 782$ grams and Length $=63.85 \pm 2.35 \mathrm{cms}$ vs. formula feed: Weight $=6922 \pm 703$ grams and Length $=63.9 \pm 1.6$ $\mathrm{cms})$. The growth was slightly better in formula feeding during first 6 months of life ${ }^{5}$

But another study also found that there is infants on breast feed have better weight gain (6712 \pm 626.5 grams) as compared to infants on formula feeding ( $6356 \pm 667$ grams), moreover, the length was also greater with breast feeding (i.e. $63.15 \pm 2.14 \mathrm{cms}$ of breast feed infants vs. $62.45 \pm 2.33 \mathrm{cms}$ of formula feed infants, $p<0.05){ }^{6}$ One study in Menoufia, Egypt reported that the infants who were exclusively breast-fed lost 14 percentiles of weight for age from birth to 6 months while those who were exclusively formula fed lost 18 percentiles. $^{15}$

Dewey showed in their study that there is no significant difference in linear growth between feeding groups. Growth in head circumference does not differ by feeding mode. Because of the difference in weight gain, breast-fed infants are generally leaner than formula-fed infants by 12 months of age. Evidence to date suggests that there are no apparent adverse consequences associated with the lower intake and slower weight gain of breast-fed infants: compared to formula-fed infants. ${ }^{16}$

Ziegler, et al. demonstrated in their study that during the first 6-8 weeks of life there was little difference in growth (gain in weight and length) between breast- and formula-fed infants. However, from about 2 months of age to the end of the first year of life formula-fed infants gain weight and length more rapidly than breastfed infants. There are no consistent differences in adiposity during the first 4-5 months of life, but during the later part of the first year of life the preponderance of the evidence suggests that breast-fed infants are leaner than formula-fed infants. ${ }^{17}$

In our study breast fed infants were $52.25 \%$ while the formula fed infants were $47.75 \%$. Some of the studies discussed here showing the incidence of breast fed infants. In 2010, HHS released Healthy People 2020, which provides updated national breastfeeding objectives for 2020, The exclusively Breastfed infants at 3 months were $46.2 \%$, and who are exclusively breastfed at 6 months to $25.5 \%$ ever breastfed to $81.9 \%$, who are breastfed at 6 months to $60.6 \%$, who are breastfed at 12 months to $34.1 \% .^{18}$

Cai, et al. showed in their study that trend data suggest the prevalence of exclusive breastfeeding among infants younger than six months in developing countries increased from $33 \%$ in 1995 to $39 \%$ in 2010 . The prevalence increased in almost all regions in the developing world, with the biggest improvement seen in West and Central Africa. ${ }^{19}$

\section{CONCLUSION}

The prevalence of exclusively breast fed infants in our study was $52.3 \%$. Our study results showed that the breast fed infants had better weight gain than formula fed infants; however no statistically significant difference was observed in the average length on breast fed and formula fed infants.

\section{REFERENCES}

1. Minniti F, Comberiati P, Munblit D, et al. Breast-milk characteristics protecting against allergy. Endocr Metab Immune Disord Drug Targets. 2014;14(1):9-15.

2. WHO 10 on breastfeeding. facts. 2014; Available from:http://www.who.int/features/ factfiles/breastfeeding/en/.

3. McAndrew F, Thompson J, Fellows L, Large A, Speed M, Renfrew MJ. Infant feeding survey 2010. Health and Social Care Information Centre. 2012. 
4. Ali S, Ali SF, Imam AM, Ayub S, Billoo AG. Perception and practices of breastfeeding of infants 0-6 months in an urban and a semi-urban community in Pakistan: a cross-sectional study. J Pak Med Assoc. 2011;61(1):99.

5. Dewey KG, Heinig MJ, Nommsen LA, Peerson JM, Lönnerdal B. Growth of Breast-Fed and Formula-Fed Infants From 0 to 18 Months: The DARLING Study. Pediatrics. 1992;89(6):1035-41.

6. Agostoni C, Grandi F, Gianni $\mathrm{M}$, et al. Growth patterns of breast fed and formula fed infants in the first 12 months of life: an Italian study. Arch Dis Child. 1999;81(5):395-9.

7. Breastfeeding and Breast Milk: Condition Information. Available from. www.nichd. nih.gov/health/topics/breastfeeding/ conditioninfo/Pages/default.aspx

8. Wagner C, Greer F. American Academy of Pediatrics Section on Breastfeeding; AmericanAcademy ofPediatrics Committee on Nutrition; American Academy of Pediatrics Section on Breastfeeding; American Academy of Pediatrics Committee on Nutrition. Prevention of rickets and vitamin $\mathrm{D}$ deficiency in infants, children, and adolescents. Prevention of rickets and vitamin $\mathrm{D}$ deficiency in in fants, children, and adolescents. Pediat rics. 2008; 122:1142-52.

9. What is weaning and how do I do it?2015,Available from: https://www. nichd.nih.gov/health/topics/breastfeeding/ conditioninfo/Pages/weaning.aspx.

10. Ip S, Chung M, Raman G, Trikalinos TA, Lau J. A summary of the Agency for Healthcare Research and Quality's evidence report on breastfeeding in developed countries. Breastfeeding med. 2009;4(S1):S-17-S-30.
11. Garner L, Black L. Breastfeeding and the use of human milk. American Academy of Pediatrics Working Group on Breastfeeding. Pediatrics. 1997;100(6):1035-9.

12. Kramer M, Kakuma R. Optimal duration of exclusive breastfeeding Cochrane Database. Syst Rev. 2009;2012(8):CD003517.

13. Agostoni C, Grandi F, Gianni M, Silano M, Torcoletti M, Giovannini M, et al. Growth patterns of breast fed and formula fed infants in the first 12 months of life: an Italian study. Arch Dis Child. 1999;81(5):395-9.

14. Ahmed EM, Ibrahim IA, Hussein AAEAM, Ahmed FA. Impact of Breast Feeding Versus Formula Feeding On Surgical Wound Healing In Infants During The First Three Months Of Age. IJSBAR. 2013;10(1):25-37.

15. Eissa A, El-Sherbini A, Khashaba A, ElBakry M, ER AA. Breast feeding and infant growth a follow-up study in Menoufia Egypt. Population Sciences. 1990;9:69-75.

16. Dewey KG. Growth characteristics of breast-fed compared to formula-fed infants. Neonatology. 1998;74(2):94-105.

17. Ziegler EE. Growth of breast-fed and formula-fed infants. Nestle Nutr Workshop Serpediatr program 2006;58:51-9.

18. Healthypeople.gov. U.S. Department of Health and Human Services. Healthy People 2020 Objectives. 2011 [cited 2015]; Available from: http:// healthypeople. gov/2020/topicsobjectives2020/pdfs/ HP2020objectives.

19. Cai X, Wardlaw T, Brown DW. Global trends in exclusive breastfeeding. Int Breastfeed J. 2012;7(1):12. 